Mink

\title{
A VACUUM ULTRAVIOLET SOURCE
}

\author{
U. FELDMAN \\ M. SWARTZ \\ L. COHEN
}

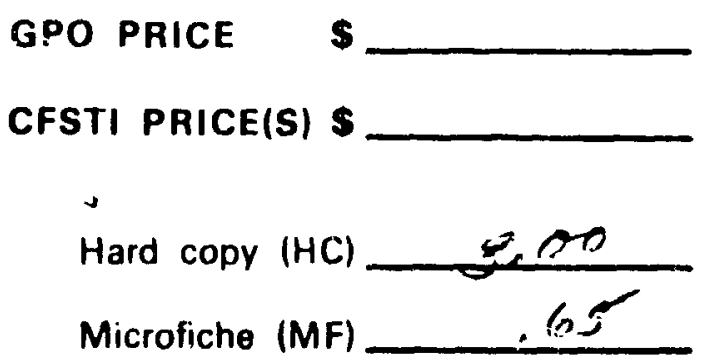

JUNE 1967.
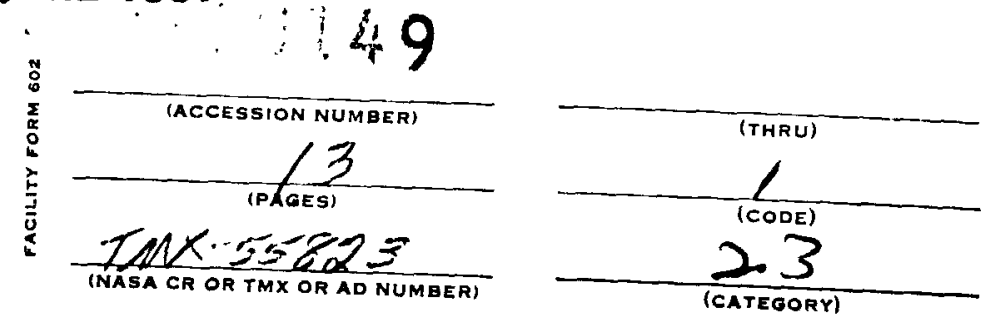

NGA

GPDDARD SPACE FLIGHT CENTER

GREENBELT, MARYLAND

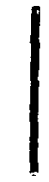




\title{
A Vacuum Ultrariolet Source \\ by
}

\author{
Uxi Feldman*, Marvin Swartz, and Leonard Cohen \\ Goddard Space Flight Center \\ Greenbelt, Maryland
}

\section{ABSTRACT}

A low inductance three-electrode spark source for the vacuum ultraviolet fed by a $20 \mathrm{kV}, 13 \mu \mathrm{f}$ capacitor is described. Its main feature is its ability to generate spectra of very high degrees of ionization. A $6 \mathrm{kV}$ spark produces spectra of $\mathrm{C} \mathrm{V}$ and $\mathrm{C}$ VI as well as Fe XVI while a 17-18 kV spark yields Fe XVIII, Al XII and Al XIII.

*NASA - National Academy of Science - National Research

Counc1l Postdoctoral Research Associate 
I INTRODUCTION

During the last decade advanees in solar physics and in plasma physics have contributed to an increased interest in the spectroscopy of the far ultraviolet. In order to generate spectra of highly ionized atoms some powerful new sources have been developed: the NRL's Pharas ${ }^{1}$, Los Alamo's Scylla $I^{2}$, Harwell's $\mathrm{Zeta}^{3}$, etc., machines which were designed to produce hot plasmas. A useful source that has been developed from this work is the theta pinch ${ }^{4}$. A laser beam has also been used to generate highly ionized atoms ${ }^{5}$. Common to these new sources are complexity and high cost, precluding their ise in an ordinary spectroscopy laboratory. In this article we describe a three electrode spark $^{6}$ version of the traditional high voltage spark source. It has the capability of producing spectra comparable to the sources mentioned above as well as spectra of low degrees of ionization. The main features of this arrangement are a comparatively low voltage with high capacitance and very low inductanee.

\section{I THREE ELECTRODE SOURCE}

For a pair of electrodes in vacuum the breakdown voltage for a separation of s.bout $1 \mathrm{~mm}$ is $50 \mathrm{kV}$ or more. It is possible to lower the breakdown voltage in a variety of ways. One such way is to provide an insulating surface between the 
electrodes along which breakdown can occur - the so-called "sliding spark"7. Low voltage rreakdown across gaps as large as a few centimeters are possible with this method. Another way is to inject charge carriers in the electrode gap to initiate a discharge. The three-electrode arrangement combines these two ideas. A third electrode is separated from the ground electrode of the spark gap by a ceramic insulator. At a predetermined time in the high voltage charging cycle a sliding spark is caused to occur along the ceramic, triggering the breakdown across the gap of the main electrodes. The nature of the sliding spark circuit is immaterial to the spectral characteristics of the main discharge. In our arrangement a Tesla coil is used, but a capacitor discharge circuit would work just as wel1. We assume a series $\mathrm{R}-\mathrm{L}-\mathrm{C}$ circuit, (Fig. 1.) where $\mathrm{C}$ is the capacitance of the energy storage capacitor, $R$ is the resistance, and $L$ the inductance of the circuit including the spark gap. For the transient case of an R-L-C circuit excited by the discharge of the initial energy stored in element $C$, it can be shown $^{8}$ that

$$
N=e^{-2 \pi \alpha / \omega}
$$

where $\mathrm{N}$ is the ratio of two consecutive maxima of the urderdamped (oscillator) current $1(t), \alpha=R / 2 L$, and $\omega=\left(\frac{1}{L C}-\frac{R^{2}}{4 L^{2}}\right)^{\frac{1}{2}}$ The time separation of these maxima is $\Delta t=2 \pi / \omega$. From oscil.. lograms made of the discharge (fig. 2) we have been able to 
measure it and $N$. Since $t$ and $N$ are functions of $R, L$ and $C_{g}$ with $C$ known, it is pussible to solve for $K$ anc $L$.

Using ous l3kf capacitor we found for our circuit $R=13 \times 10^{-3}$ : and $L-160 \times 10^{-9}$ henry. A typical voltage of $18 \mathrm{kV}$ would produce, therefore an $I_{\max }$ of about 150,000 amperes.

\section{MECHANICAL DESCR IPTION}

The chamber itself is constructed of stainless steel (Fig. 2:3) and is roughly cube-shaped. The most important characteristics however are its short path length to the capacitor and the configuration of the electrode connections. The energy storage capacitor is mounted a few inches; below the chamber and connects with the chamber via cylindrically symmetrical feedthroughs. The results is a circuit with negligible resistance and low inductance. The insulators have been designed to withstand up to $50 \mathrm{kV}$ although we have not yet found it necessary to even approach this limit in order to get the spectra we are interested in. The chamber connects with the auxiliary pumping system via a port in its left side. The top and right side of the chamber are fitted with ports that are used for gauges, additional electrodes, test probes, etc. The front plate which exposes the inside of the chamber for changing electrodes, contains a cold trap and a window for observation during operation. A thin gate valve separates the chamber from the spectrometer, and another valve separates it from the pumps. This enables us to isolate the chamber and 
chang: electrodes or otherwise service the inside of the chamuer withot. breaking vacus in the spectrometer.

\section{RESULTS}

By operating the source at $12.18 \mathrm{kV}$ we have recorded spectra of the $\mathrm{Na} \mathrm{I,} \mathrm{Ne} \mathrm{I} \mathrm{and} \mathrm{F} \mathrm{I} \mathrm{isoelectronic} \mathrm{sequences}$ for elements from scandium to $z$ inc, in the wavelength range of $8 \AA$ to $60 \AA$.

Spectra of AI XII and XIII down to $6 \&$ were produced with a $17 \mathrm{kV}$ discharge. Voltages as low as $6 \mathrm{kV}$ produce spectra of $\mathrm{C} V$ and $C$ VI between $26 \AA-40 \AA$. It is possible to distinguish between the different degrees of ionization by comparing spectrograms taken at different voltages. Increasing the voltage increases the intensities of the higher degrees with respect to the lower degrees of ionization. For instance, in iron the highest degree of ionization for a $6 \mathrm{kV}$ spark was found to be Fe XVI, for $12 \mathrm{KV} \mathrm{Fe} \mathrm{XVII} \mathrm{was} \mathrm{the}$ highest degree observed, and for $18 \mathrm{kV}$, Fe XVIII and probably higher degrees of tonization were recorded. Increasing the inductance by very small amounts would tend to emphasize lower degrees of ionization.

All of the spectrograms were recorded on Kodak SWR plates using a modified Jarre1l-Ash, 3 meter, $88^{\circ}$ angle of incidence spectrometer, using a B\&L $1200 \mathrm{l} / \mathrm{mm}$ blazed gold replica grating $^{9}$. The number of sparks necessary to produce strong 
spectrograms was from fifty to one hundred.

\section{ACKNOWLEDGEMENT}

The authors would like to acknowledge the assistance of: Richard Ugiansky and John Pimlott in designing the chamber and its accessories. 


\section{REFERENCES}

1. R. C. Elton, E. Hintz, M. Swartz, Proc. Seventr International Conferenre on Phenomena in Ionized Gases, Belgrade, 1965. A. C. Kolb, et al, Proc. Second international Conference on Plasma Physics and Controlled Nuclear Fusion Research, Culham. 1965.

2. A, J. Bearden, et al, Phys. Rev. Letters 6, 257, (1961).

3. B. C. Fawcett, et al, Nature, 200, 1963 .

4. G. A. Sawyer, et a1, phys. Rev. 131, 1891 (1963).

5. B. C. Fawcett, A. H. Gabriel, P.A.H. Saunders, Proc. Phys. Soc. 90, 863 (1967).

6. G. Balloffet, Ann. Phys. Paris 5, 1243 (1960).

7. B. Vodar and N. Astoin, Nature, 166, 1029 (1950).

8. See for instance, G. Harnwel1, Principles of Electricity and Magnetism, 2nd ed. McGraw-Hill, N. Y. (1949), p 460 .

9. These results are reported elsewhere in greater detail. See U. Feldman, L, Cohen and M. Swartz, J.O.S.A. 57 535 (1967), Astrophys $J$. Vol 148, 585 (1967), U. Feldman and L. Cohen, Astrophys. J. (to be published). 


\section{FIGURF: CAPTIONS}

Figure 1 - Schrmitic diagram of the dischargo corcuit, where PS is the power supply, $R_{c h}$ and $L_{c h}$ are the reststance and inductance of the charging circuit, respectively, $C$ is a $13 \mu f-20 \mathrm{kV}$ capacitor. $L_{1}$ is the inductance of the capacitor, and $L_{2}$ is the inductance of the transmission line and the chamber.

Figure 2 - Front view of the spark chamber with the cover removed. Visible to the rear of the chamber are the entrance slit housing, and the gate valve that isolates the chamber from the spectrometer. The arrow Indicates the direction of the chamber pumbing system. Ports in the top and side accomodate vacuum gauges and the electrical connection to the Tesla coll alrcuit. The positive conductor from the capacitor enters the chamber axially through the Delrin insulator. The removable electrode holder and the electrode are just visible in the window of the cap which is part of the negative (ground) conductor. The negative conductor is concentric with the positive conductor and also enters the chamber through the Delrin insulator. 
The cap is removable and contains the negative eloctrode, concentric ceramic insulator, and the trigger clectrode that is energized by a Tesla coil. The chamber dimensions are approximately $7 " \times 8 " \times 7 "$.

Figure 3 - Side view schematic diagram of the spark chamber and capacitor. Omitted from the diagram for the sake of clarity are ports in the top and side and the cold trap which is part of the removable cover. The cross-section of the chamber is approximately 7" $x$ 7". The capacitor is not drawn to scale. 


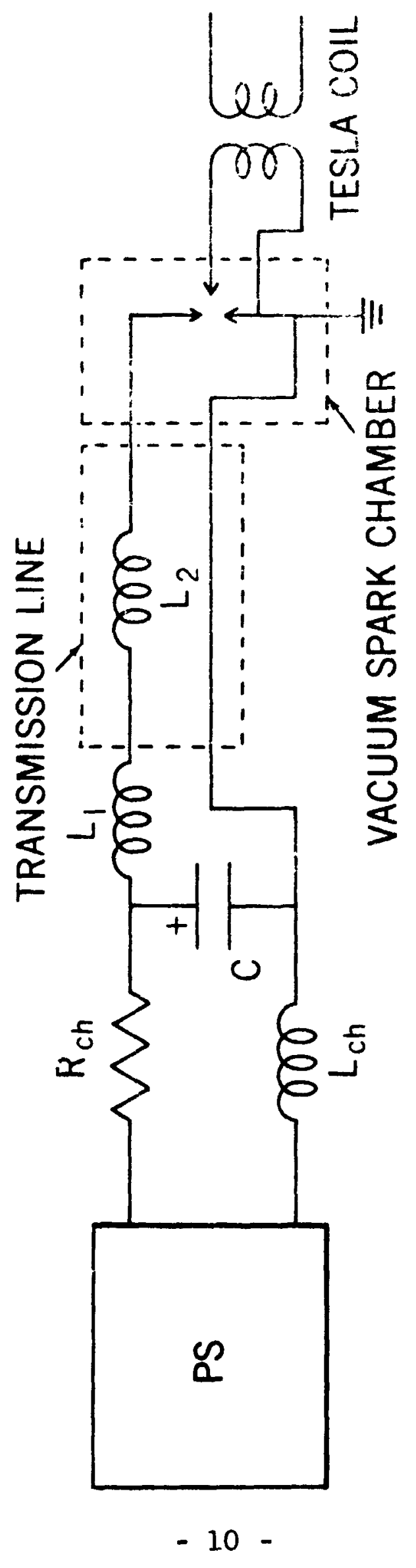

秥 


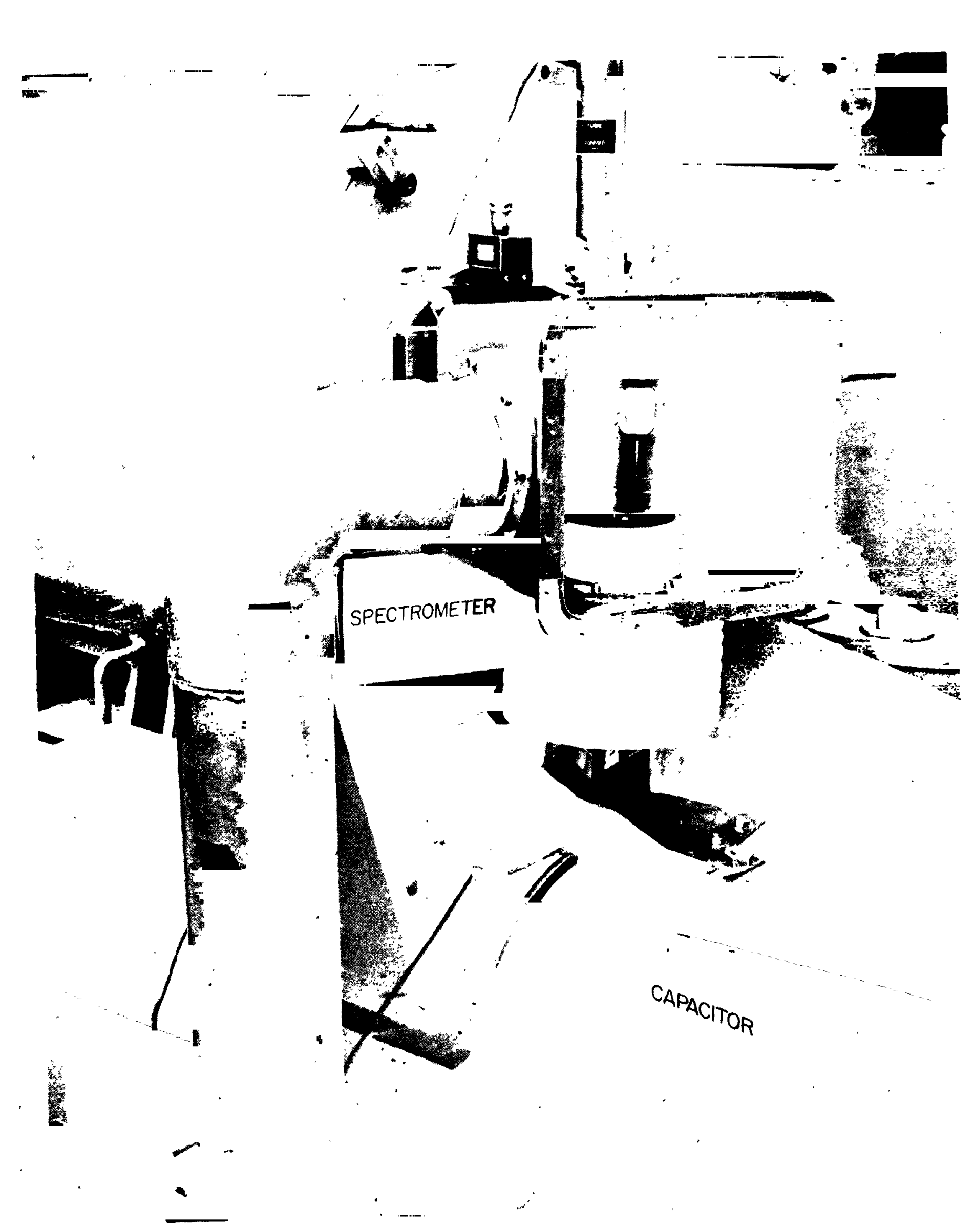

FIGURE 2

- 11 - 


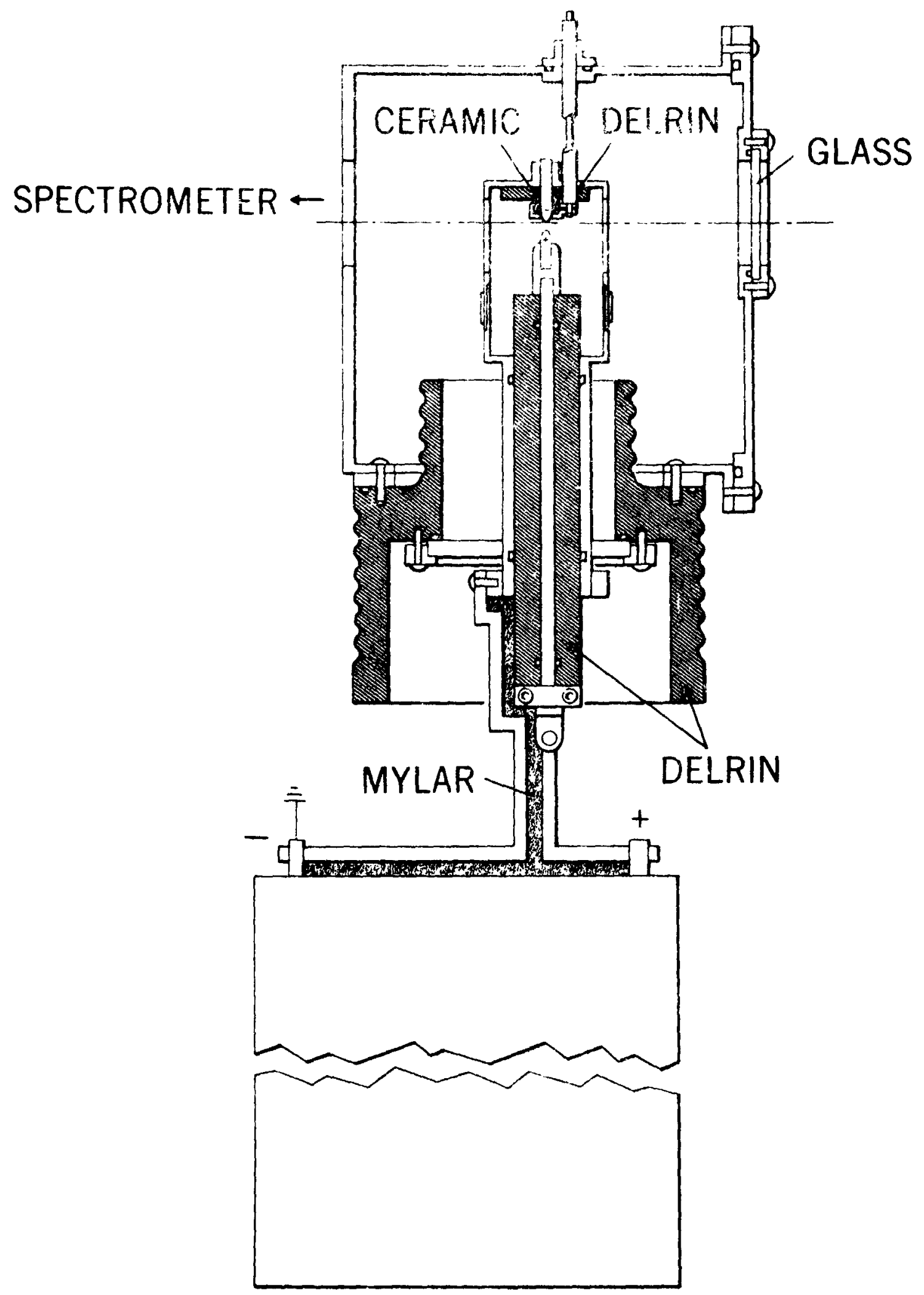

FIGURE 3 